\title{
MICROWAVE-ASSISTED EXTRACTION OF PHENOLIC COMPOUNDS FROM GINGER (ZINGIBER OFFICINALE ROSC.)
}

\author{
Le Pham Tan Quoc ${ }^{1 凶}$ \\ ${ }^{I}$ Institute of Biotechnology and Food Technology, Industrial University of Ho Chi Minh City, Ho Chi Minh City, \\ Vietnam \\ ${ }^{凶}$ lephamtanquoc@iuh.edu.vn \\ https://doi.org/10.34302/crpifst/2020.12.1.16

\begin{tabular}{|c|c|}
\hline Article history: & \multirow{11}{*}{$\begin{array}{l}\text { ABSTRACT } \\
\text { The main purpose of this study is to determine the best microwave-assisted } \\
\text { extraction conditions such as type of solvent, solvent concentration, } \\
\text { material/solvent ratio, microwave of power and extraction time. These } \\
\text { factors affect strongly total polyphenol content (TPC) and antioxidant } \\
\text { activity (AC). The achieved best parameters for the extraction process were } \\
\text { aqueous ethanol concentration of } 50 \% \text {, material/solvent ratio of } 1 / 40(\mathrm{w} / \mathrm{v}) \text {, } \\
\text { extraction time of } 3 \mathrm{minutes} \text { and microwave power of } 127 \mathrm{~W} \text {. TPC and AC } \\
\text { peaked at } 22.79 \pm 0.29 \mathrm{mg} \mathrm{GAE} / \mathrm{g} \mathrm{DW} \text { and } 9.85 \pm 0.03 \mathrm{mmol} \mathrm{Fe} / \mathrm{g} \mathrm{DW} \text {, } \\
\text { respectively. Besides, the treatment by microwave can affect the cell } \\
\text { structure of material which was observed by scanning electron microscope } \\
\text { (SEM). }\end{array}$} \\
\hline Received: & \\
\hline 25 April 2019 & \\
\hline Accepted: & \\
\hline 10 January 2020 & \\
\hline Keywords: & \\
\hline Antioxidant; & \\
\hline Extraction; & \\
\hline Ginger; & \\
\hline Microwave; & \\
\hline Polyphenols. & \\
\hline
\end{tabular}

\section{Introduction}

Ginger is the herbal plant and precious spice for humans. Ginger (Zingiber officinale Rosc.) belongs to the Zingiberaceae family and distributes everywhere in Vietnam. Local citizens usually use fresh or dried ginger root as a spice (Do, 2014). Ginger is also an antioxidant food and good for human health. Ginger root contains many bioactive compounds such as flavonoids, tannins, $\beta$ carotene and vitamin $\mathrm{C}$ which have a strong antioxidant capacity (Shirin and Prakash, 2010). Besides, ginger also has many uses to treat many diseases such as nausea, cough, digestive aid, inflammation, swelling (Truong, 2001), digestion, treatment of bronchitis (Pham, 2014). It can slow down or prevent the development of cancerous tumors, etc. In addition, ginger roots extract contains an amount of polyphenols compounds as high antioxidant agents. The antioxidant properties of ginger root are an extremely important activity, they can be used as a preventative agents against certain diseases. In addition, ginger also has antibacterial effects and inhibits the growth of Escherichia coli, Proteus sp., Staphylococci and Salmonella (Gupta and Sharma, 2014).

Nowadays, there are some methods to extract phenolic compounds from the plant such as maceration, soxhlet, ultrasound-assisted extraction (UAE), microwave-assisted extraction (MAE), etc. However, the demands of a good extraction method are environmentally friendly (reduced use of organic solvents), saved time and increased extraction yield (Hue, 2002). In there, MAE is the method that can adapt these demands and it was used in many previous studies to extract phenolic compounds from the plants, for instance, tea (Pan et al., 2003), rosemary (Švarc-Gajic et al., 2013), Polygonum multiflorum Thunb. roots (Quoc and Muoi, 2016), etc. In addition, according to Wakte et al. (2011), MAE used a low amount of solvent, reduced production costs and had high-quality products compared to other methods. Therefore, using the MAE method has many 
benefits in food technology and chemical technology.

Until now, no studies have presented the MAE method for the extraction of phenolic compounds from ginger in Vietnam and evaluate the effects of extraction factors on TPC and AC. Hence, based on the above judgment, this study investigates the extraction conditions of phenolic compounds from the ginger extract supported by microwaves such as type of solvent, solvent concentration, the ratio of material/solvent, extraction time and microwave power.

\section{Materials and methods}

\subsection{Plant material and sample preparation}

Ginger (Zingiber officinale) were harvested from Nghe An province (Vietnam), cleaned and then sliced $(2 \mathrm{~mm})$ and dried at $60^{\circ} \mathrm{C}$ for nearly 5 hours until the moisture is lower than $12 \%$. The slices were ground into a fine powder $(<0.5 \mathrm{~mm})$, packed in vacuum and then stored in the dark at room condition $\left(25^{\circ} \mathrm{C}\right)$.

\subsection{Chemicals and reagents}

Gallic acid and Folin-Ciocalteu (FC) reagent were purchased from Sigma-Aldrich (USA). All organic solvents and other chemicals were of analytical reagent grade.

\subsection{Polyphenols extraction process}

Dried ginger powder $(2 \mathrm{~g})$ is extracted in four solvents such as $50 \%$ ethanol, $50 \%$ acetone, $50 \%$ methanol and deionized water. Appropriate solvents will be carried out at different solvent concentrations of 30, 40, 50, 60 and $70 \%(\mathrm{v} / \mathrm{v})$; the ratios of material/solvent are $1 / 20,1 / 30,1 / 40,1 / 50$ and 1/60 (w/v); microwave power are $74,127,195,327,610$ $\mathrm{W}$; extraction times are 1, 3, 5, 7 and 9 minutes, respectively. The extract is filtered for removal of the residue by the vacuum filtration system, then TPC and AC of extract were determined.

\subsection{Determination of total polyphenol content (TPC)}

The TPC in the extract was slightly modified and determined by the Folin-
Ciocalteu method. The results were based on a standard curve obtained with gallic acid measured at $738 \mathrm{~nm}$ (Siddiqua et al., 2010). TPC was calculated as milligram of gallic acid equivalent per gram of dry weight (mg GAE/g DW).

\subsection{Determination of antioxidant capacity (AC)}

The AC in the extract is determined by the slightly modified method of the 1.10phenanthroline solution in methanol. The reaction between $\mathrm{Fe}$ (II) and 1,10phenanthroline forms complex orange-red complexes. AC was measured by a standard curve obtained at a wavelength of $510 \mathrm{~nm}$. Antioxidant activity was expressed as $\mathrm{mmol} \mathrm{Fe}$ equivalents per gram of dry weight $(\mathrm{mmol} \mathrm{Fe} / \mathrm{g}$ DW) (Szydowska-Czerniak et al., 2008; Songsungkan and Chanthai, 2014).

\subsection{Scanning electron micrographs (SEM)}

Ginger powder was observed by SEM (Jeol/JSM-6480LV, Japan) to indicate changes of the material in particle morphology before and after extraction.

\subsection{Data analysis}

All experiments were performed in triplicates, the results were expressed in the form of mean \pm standard deviation (SD) and analyzed by the Statgraphics Centurion XV software, version 15.1.02 (USA). The one-way analysis of variance (ANOVA) at $\rho<0.05$ was used to determine significant differences between the means by LSD (Fisher's least significant difference) method.

\section{Results and discussions}

\subsection{Effect of solvent type on the extraction of polyphenols}

The dried ginger powder was extracted with four solvents (deionized water, 50\% acetone, $50 \%$ ethanol and $50 \%$ methanol) under the same extraction condition as follows: sample/solvent ratio of 1/30 (w/v), microwave power of $195 \mathrm{~W}$ and extraction time of 5 minutes. The results are shown in Table 1 below. 
Table 1 shows that there are significant differences between different types of solvents regarding TPC as well as AC $(\rho<0.05)$ and the extraction yield of solvents reduces in order of $50 \%$ ethanol $>50 \%$ methanol $>50 \%$ acetone $>$ deionized water. For using ethanol as solvent, TPC and AC obtained the highest values $(18.87 \pm 0.23 \mathrm{mg}$ GAE$/ \mathrm{g}$ DW and $9.05 \pm 0.14$ $\mathrm{mmol} \mathrm{Fe/g} \mathrm{DW,} \mathrm{respectively),} \mathrm{while} \mathrm{the} \mathrm{lowest}$ values of TPC and AC were $9.72 \pm 0.22 \mathrm{mg}$ GAE/g DW and $2.84 \pm 0.06 \mathrm{mmol} \mathrm{Fe} / \mathrm{g} \mathrm{DW}$, respectively, for using water as solvent. The differences between TPC and AC may occur because the polarities of solvents are completely different. In this case, the best extractable polarity is the ethanol concentration of $50 \%$, which is similar to the study results concerning the extraction of TPC on the pomegranate peel (Kaderides et al., 2019).
In fact, there are many solvents that can extract phenolic compounds, they depend on the purpose of use. Typically, this research result shows that the TPC is higher than that of Kubra et al. (2013), they also extracted phenolic compounds (TPC $=16.4 \pm 0.2 \mathrm{mg}$ GAE/g DW) from ginger with $50 \%$ ethanol as solvent by MAE method. Besides, the TPC of this case is lower than that of other material with the same solvent, for instance, pomegranate peels (Kaderides et al., 2019), Limnophila aromatica (Do et al., 2014). These differences can be due to different materials, extraction methods, genes, etc. At present, ethanol was used in many previous studies because of its advantages such as low cost, clean and safe solvent in food. Based on the results obtained, $50 \%$ ethanol is selected as the solvent for the next test.

Table 1. TPC and AC of extract at different solvents

\begin{tabular}{|c|c|c|c|c|}
\hline & \multicolumn{4}{|c|}{ Solvents } \\
\cline { 2 - 5 } & Deionized water & $\mathbf{5 0 \%}$ Acetone & $\mathbf{5 0 \%}$ Ethanol & $\mathbf{5 0 \%}$ Methanol \\
\hline TPC (mg GAE/g DW) & $9.72^{\mathrm{a}} \pm 0.22$ & $13.06^{\mathrm{b}} \pm 0.36$ & $18.87^{\mathrm{d}} \pm 0.23$ & $18.02^{\mathrm{c}} \pm 0.42$ \\
\hline AC (mmol Fe/g DW) & $2.84^{\mathrm{a}} \pm 0.06$ & $6.02^{\mathrm{b}} \pm 0.21$ & $9.05^{\mathrm{d}} \pm 0.14$ & $7.68^{\mathrm{c}} \pm 0.27$ \\
\hline
\end{tabular}

Different lowercase letters in the same row indicate a statistically significant difference between various solvents $(\rho<0.05)$

\subsection{Effect of ethanol concentration on the extraction of polyphenols}

The effects of ethanol concentration on TPC and AC were illustrated in Table 2. The results show that there is a statistically significant difference between various ethanol concentrations with $\rho<0.05$. The TPC reaches the highest value at ethanol concentration of $70 \%$ (24.28 $\pm 0.55 \mathrm{mg}$ GAE/g DW), while the AC obtains the best value at ethanol concentration of $50 \%(9.08 \pm 0.07 \mathrm{mmol} \mathrm{Fe} / \mathrm{g}$ DW). Hence, the level of changes between TPC and $\mathrm{AC}$ is not identical in this case.

The ethanol concentration plays a major role in polyphenols extraction and the high ethanol concentrations can cause the protein denaturation, prevent the dissolution of polyphenols and thus it affects the rate of the extraction process (Yang et al., 2009). It can be seen that the changes in any parameter do not mean that TPC and AC will increase or decrease accordingly. Both of TPC and AC depend on many factors, especially the polarity of the solvent. The addition of water into the solvent often creates the changes of polarity and phenolic compounds were easily dissolved into the solvent. Solvent properties in this study were changed by a combination of ethanol and water. Choosing the appropriate solvent concentration can improve TPC and AC; minimizes the extraction expenditure and limits unwanted impurities (Tomaz et al., 2019).

This result is similar to studies of Kaderides et al. (2019) and Kubra et al. (2013), which also shows that ethanol concentration of $50 \%$ is the suitable solvent concentration to extract phenolic compounds from pomegranate peels and ginger. In contrast, Quan et al. (2006) and Dahmoune et al. (2015) noticed that the optimal ethanol concentration to extract 
phenolic compounds from fresh tea shoot and Myrtus communis L. leaves are $40 \%$ and $60 \%$, respectively. This can be explained because of the different polarities of phenolic compounds in materials. Through the received results, the ethanol concentration of $50 \%$ was selected to carry out the subsequent studies.

Table 2. TPC and AC of extract at different ethanol concentrations

\begin{tabular}{|c|c|c|c|c|c|}
\hline & \multicolumn{5}{|c|}{ Ethanol concentration (\%) } \\
\cline { 2 - 6 } & $\mathbf{3 0}$ & $\mathbf{4 0}$ & $\mathbf{5 0}$ & $\mathbf{6 0}$ & $\mathbf{7 0}$ \\
\hline TP $(\mathbf{m g}$ GAE/g DW) & $11.74^{\mathrm{a}} \pm 0.03$ & $14.34^{\mathrm{b}} \pm 0.11$ & $18.67^{\mathrm{c}^{\mathrm{d}}} \pm 0.22$ & $22.78^{\mathrm{d}} \pm 0.39$ & $24.28^{ \pm} \pm 0.55$ \\
\hline AC (mmol Fe/g DW) & $1.59^{\mathrm{a}} \pm 0.35$ & $1.99^{\mathrm{b}} \pm 0.12$ & $9.08^{\mathrm{d}} \pm 0.07$ & $6.27^{\mathrm{c}} \pm 0.22$ & $6.17^{\mathrm{c}} \pm 0.14$ \\
\hline
\end{tabular}

Different lowercase letters in the same row indicate a statistically significant difference between various ethanol concentrations $(\rho<0.05)$

\subsection{Effect of material/solvent ratio on the extraction of polyphenols}

The effect of material/solvent ratio on TPC and $\mathrm{AC}$ was presented in Table 3. TPC and AC have a statistically significant difference $(\rho<0.05)$ for the changes in the material/solvent ratios. TPC and AC have the highest values $(21.82 \pm 0.38 \mathrm{mg}$ GAE$/ \mathrm{g}$ DW and $9.76 \pm 0.53$ mmol Fe/g DW, respectively) at the material/solvent ratio of $1 / 40$.

The ratio of raw material/solvent is an important parameter of the extraction method and affects TPC and AC strongly. The volume of solvent must be sufficient to ensure the entire sample is soaked in solvent. For the MAE method, an increase in excessive solvent volume will reduce microwave adsorption of material mainly because the solvent absorbed almost all energy of the microwave. Therefore, the breakdown of the cell wall and mass transmission might be negatively affected ( $\mathrm{Li}$ et al., 2010). In addition, material size has a significant effect on extraction efficiency. Smaller materials reduce cell diffusion distance in solids, increase the concentration of the gradient, thereby leads to higher extraction rates (Tomaz et al., 2019).

The material/solvent ratio of this study is lower than that of study of Calinescu et al. (2017), who extracted polyphenols from sea buckthorn leaves at the material/solvent ratio of $1 / 20$ with microwave support combined with a coaxial antenna and a cooling system; this ratio also is similar to that of study of Quoc and Muoi (2016), they extracted polyphenols from Polygonum multiflorum Thunb. roots and it is higher than that of the study of Kaderides et al. (2019), who extracted polyphenols from pomegranate peels at the material/solvent ratio of 1/60 with MAE method. It can be seen that different materials can produce different proportions of material/solvent. Through the above research results, the material/solvent ratio of $1 / 40$ was selected for the next steps.

Table 3. TPC and AC of extract at different material/solvent ratios

\begin{tabular}{|c|c|c|c|c|c|}
\hline \multirow{2}{*}{} & \multicolumn{5}{|c|}{ Material/solvent ratios (w/v) } \\
\cline { 2 - 6 } & $\mathbf{1 / 2 0}$ & $\mathbf{1 / 3 0}$ & $\mathbf{1 / 4 0}$ & $\mathbf{1 / 5 0}$ & $\mathbf{1 / 6 0}$ \\
\hline TPC (mg GAE/ g DW) & $15.49^{\mathrm{a}} \pm 0.27$ & $18.53^{\mathrm{b}} \pm 0.31$ & $21.82^{\mathrm{d}} \pm 0.38$ & $21.97^{\mathrm{d}} \pm 0.25$ & $21.12^{\mathrm{c}} \pm 0.17$ \\
\hline AC (mmol Fe/g DW) & $6.68^{\mathrm{c}} \pm 0.02$ & $8.80^{\mathrm{d}} \pm 0.24$ & $9.76^{\mathrm{c}} \pm 0.53$ & $5.38^{\mathrm{b}} \pm 0.05$ & $4.67^{\mathrm{a}} \pm 0.21$ \\
\hline
\end{tabular}

Different lowercase letters in the same row indicate a statistically significant difference between various material/solvent ratios $(\rho<0.05)$

3.4. Effect of microwave power on the extraction of polyphenols

Table 4 shows that the maximum TPC and AC were $22.37 \pm 0.19 \mathrm{mg} \mathrm{GAE} / \mathrm{g}$ DW and
$9.20 \pm 0.2 \mathrm{mmol} \mathrm{Fe} / \mathrm{g} \quad \mathrm{DW}$ at $127 \mathrm{~W}$, respectively. Microwave power significantly affects TPC and AC $(\rho<0.05)$. Extraction temperature depends on microwave power in 
this case; as the microwave power increases, the solution temperature also increases. The yield of the process increases correlatively from $74 \mathrm{~W}$ to $127 \mathrm{~W}$ and then drops slowly during the rest scale because the sensitive phenolic compounds are degraded at high temperature.

At the high temperature, surface tension and solvent viscosity decrease, the solvent has high dissolve ability, which improves extraction yield (Li et al., 2010). Thereout, the microwave irradiation redoubles the rate of cell destruction by the internal pressure increase the plant cell, which promotes the destruction of the sample surface and diffuses free compounds in the plant cells into the surrounding solvent (Maran et al., 2014).

The microwave power of $127 \mathrm{~W}$ is not high and quite suitable for this study because using low microwave power with extending extraction time can improve the extraction yield. In contrast, high microwave power could reduce purity and create very high temperatures leading to the degradation of phenolic compounds (Liew et al., 2016). This may explain that the high irradiation power provides residual energy for solvent and it disturbs molecular interactions (Maran et al., 2015).

The microwave power of this study was similar to that of the study of Quoc and Muoi (2016), who extracted the phenolic compounds from Polygonum multiflorum Thunb. roots. Besides, it is higher than that of study of Bouras et al. (2015), they extracted the phenolic compounds from Quercus bank at the optimal microwave power of $45 \mathrm{~W}$, while Kaderides et al. (2019) extracted the phenolic compounds from pomegranate peels at the optimal microwave power of $600 \mathrm{~W}$. This may also explain that the structure of the initial raw materials and type of polyphenols in materials are different leading to the difference of microwave power. Thus, the microwave power of $127 \mathrm{~W}$ was chosen for subsequent studies.

Table 4. TPC and AC of extracts at various microwave powers

\begin{tabular}{|c|c|c|c|c|c|}
\hline & \multicolumn{5}{|c|}{ Microwave powers (W) } \\
\cline { 2 - 6 } & $\mathbf{7 4}$ & $\mathbf{1 2 7}$ & $\mathbf{1 9 5}$ & $\mathbf{3 2 7}$ & $\mathbf{6 1 0}$ \\
\hline TPC (mg GAE/g DW) & $17.52^{\mathrm{a}} \pm 0.38$ & $22.37^{\mathrm{d}} \pm 0.19$ & $21.76^{\mathrm{c}} \pm 0.43$ & $20.28^{\mathrm{b}} \pm 0.18$ & $17.69^{\mathrm{a}} \pm 0.13$ \\
\hline AC (mmol Fe/g DW) & $5.33^{\mathrm{a}} \pm 0.19$ & $9.20^{\mathrm{d}} \pm 0.2$ & $8.91^{\mathrm{c}} \pm 0.22$ & $8.78^{\mathrm{c}} \pm 0.14$ & $8.23^{\mathrm{b}} \pm 0.13$ \\
\hline
\end{tabular}

Different lowercase letters in the same row indicate a statistically significant difference between various microwave powers $(\rho<0.05)$

\subsection{Effect of extraction time on the extraction of polyphenols}

The result of the study shows the changes of TPC and AC when the extraction time changes from 1 to 9 minutes (Table 5). At 3 minutes, the TPC and AC have the best values $(22.79 \pm 0.29 \mathrm{mg}$ GAE$/ \mathrm{g}$ DW and $9.85 \pm 0.03$ $\mathrm{mmol} \mathrm{Fe} / \mathrm{g} \mathrm{DW}$, respectively). Extraction yield depends on the extraction time; as the extraction time increases, the extraction yield also increases. However, the extraction yield in this study decreases after 3 minutes because the sensitive phenolic compounds are destroyed at high temperatures and long extraction time. Thus, choosing appropriate extraction time can improve extraction efficiency as well as shorten the time, saved cost.
This result is similar to that of an extraction study by the MAE method from pomegranate peel of Kaderides et al. (2019). However, the extraction time in this case is shorter than that of many previous studies from various materials, for instance, extracting polyphenols from Polygonum multiflorum Thunb. roots for 5 minutes (Quoc and Muoi, 2016), Quercus bark for 60 minutes (Bouras et al., 2015), sour cherry Marasca for 9 minutes (Garofulic et al., 2013); while it is longer than that of study of $\mathrm{Wu}$ et al. (2012), who extracted polyphenols from potato downstream wastes by MAE method for 2 minutes.

Basically, the MAE method is a good extraction process with effective microwave energy transmission to material by molecular interaction under electromagnetic fields in a 
short time compared to conventional methods. Energy is quickly transferred to solvent and material. However, extending extraction time causes degradation of compounds and extraction yield (Huang et al., 2017).
Nevertheless, the short extraction time can not completely extract the desired compounds. Therefore, the extraction time of 3 minutes is the best choice in this study.

Table 5. TPC and AC extracts at various extraction times

\begin{tabular}{|l|c|c|c|c|c|}
\hline & \multicolumn{5}{|c|}{ Extraction time (min) } \\
\cline { 2 - 6 } & $\mathbf{1}$ & $\mathbf{3}$ & $\mathbf{5}$ & $\mathbf{7}$ & $\mathbf{9}$ \\
\hline TPC (mg GAE/g DW) & $21.21^{\mathrm{b}} \pm 0.24$ & $22.79^{\mathrm{d}} \pm 0.29$ & $21.88^{\mathrm{c}} \pm 0.33$ & $21.62^{\mathrm{bc}} \pm 0.33$ & $19.69^{\mathrm{a}} \pm 0.21$ \\
\hline AC (mmol Fe/g DW) & $9.62^{\mathrm{d}} \pm 0.04$ & $9.85^{\mathrm{d}} \pm 0.03$ & $8.69^{\mathrm{c}} \pm 0.36$ & $7.84^{\mathrm{b}} \pm 0.06$ & $4.92^{\mathrm{a}} \pm 0.06$ \\
\hline
\end{tabular}

Different lowercase letters in the same row indicate a statistically significant difference between various extraction times $(\rho<0.05)$

\subsection{Effect of microwave assisted extraction on structure of material}

Based on the obtained results, it was found that the structure of ginger powder before and after the extraction was different at $\times 2000$ magnification. In the beginning, the ginger powder had an intact structure (Figure 1A). After the microwave-assisted extraction, few cells are ruptured and the cell wall is damaged and sticky, specifically, the surface was peeled and cracked (Figure 1B). However, these changes are not significant compared to the initial material. These changes are similar to the study of Quoc and Muoi (2016), who used the MAE methods to extract polyphenols from

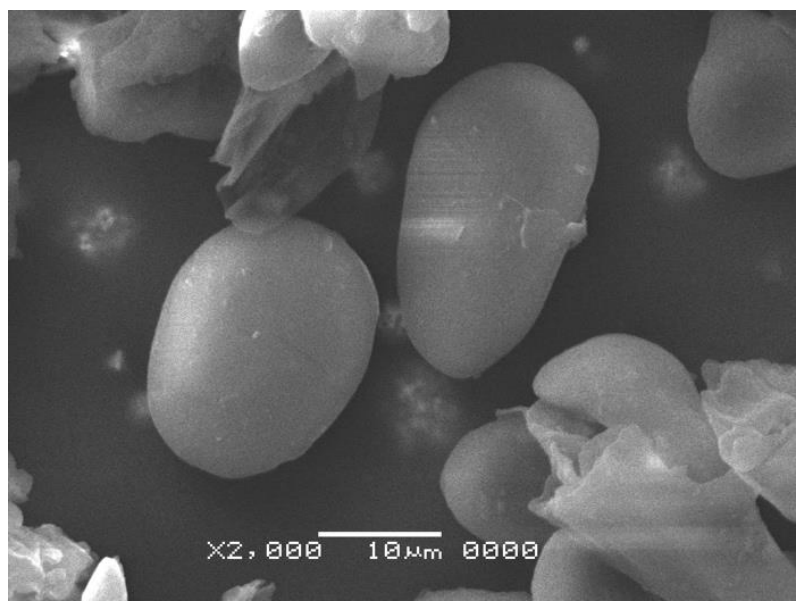

A
Polygonum multiflorum Thunb. roots. In addition, this phenomenon in the MEA method is also similar to the UEA method, for instance, extracting polyphenol from Myrtus communis by the UEA method allows solvents to penetrate the cell walls and the bubbles produced by acoustic cavitation aid in the disruption of the cell wall (Xia et al., 2011). The changes in the shape of material occur due to the following causes: the temperature and the internal pressure increases dramatically because of microwave energy in the extraction process leading to break the cell wall and releases bioactive compounds.

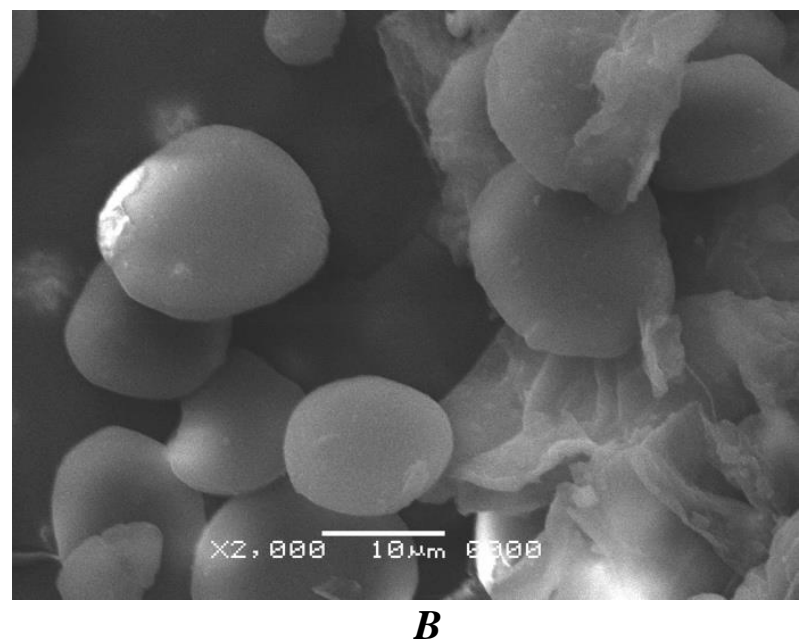

B

Figure 1. Structure of material before (A) and after (B) treatment by MAE

\section{Conclusions}

Ginger is rich in phenolic compounds with high antioxidant activity. The results proved that the extraction factors directly affect total polyphenol content and antioxidant capacity. The best extraction conditions are ethanol 
concentration of $50 \%$, material/solvent ratio of 1/40, microwave power of $127 \mathrm{~W}$ and extraction time of 3 minutes. Total polyphenol content and antioxidant capacity of the extract obtain the highest value. After microwave treatment, the cell wall of the material changes insignificantly.

\section{References}

Bouras, M., Chadni, M., Barba, F.J., Grimi, N., Bals, O., Vorobiev, E. (2015). Optimization of microwave-assisted extraction of polyphenols from Quercus bark. Industrial Crops and Products, 77, 590-601.

Calinescu, I., Lavric, V., Asofiei, I., Gavrila, A.I., Trifan, A., Ighigeanu, D., Martin, D., Matei, C. (2017). Microwave assisted extraction of polyphenol using a coaxial antenna and cooling system. Chemical Engineering and Processing, 122, 373-379.

Dahmoune, F., Nayak, B., Moussi, K., Remini, H., Madani, K. (2015). Optimization of microwave-assisted extraction of polyphenols from Myrtus communis L. leaves. Food Chemistry, 166, 585-595.

Do, Q.D, Angkawijaya, A.E., Tran-Nguyen, P.L., Huynh, L.H., Soetaredjo, F.E., Ismadji, S., Ju, Y.H. (2014). Effect of extraction solvent on total phenol content, total flavonoid content, and antioxidant activity of Limnophila aromatica. Journal of Food and Drug Analysis, 22(3), 296302.

Do, T.L. (2004). Những cây thuốc và vị thuốc Việt Nam [Herbal plants and its remedies in Vietnam]. Hanoi: Medical Publishing House. (In Vietnamese)

Garofulic, I.E., Dragovic-Uzelac, V., Jambrak, A.R., Jukic, M. (2013). The effect of microwave assisted extraction on the isolation of anthocyanins and phenolic acids from sour cherry Marasca (Prunus cerasus var. Marasca). Journal of Food Engineering, 117(4), 437-442.

Gupta, K.S., Sharma, A. (2014). Merdicinal properties of Zingiber officinale Roscoe - A Review. IOSR Journal of Pharmacy and Biological Sciences, 9(5), 124-129.
Huang, J., He, W., Yan, C., Du, X., Shi, X. (2017). Microwave assisted extraction of flavonoids from pomegranate peel and its antioxidant activity. $B I O \quad W e b$ of Conferences, 8, 1-6.

Huie, C.W. (2002). A review of modern sample preparation techniques for the extraction and analysis of medicinal plants. Analytical and Bioanalytical Chemistry, 373(1-2), 23-30.

Kaderides, K., Papaoikonomou, L., Serafim, M., Goula, A.M. (2019). Microwaveassisted extraction of phenolics from pomegranate peels: Optimization, kinetics, and comparison with ultrasounds extraction. Chemical Engineering and Processing - Process Intensification, 137, $1-11$.

Kubra, I.R., Kumar, D., Rao, L.J.M. (2013). Effect of microwave-assisted extraction on the release of polyphenols from ginger (Zingiber officinale). International Journal of Food Science and Technology, 48, 18281833.

Li, J., Zu, Y.G., Fu, Y.J., Yang, Y.C., Li, S.M., Li, Z.N., Wink, M. (2010). Optimization of microwave-assisted extraction of triterpene saponins from defatted residue of yellow horn (Xanthoceras sorbifolia Bunge.) kernel and evaluation of its antioxidant activity. Innovative Food Science and Emerging Technologies, 11(4), 637-643.

Liew, S.Q., Ngoh, G.C., Yusoft, R., Teoh, W.H. (2016). Sequential ultrasoundmicrowave assisted acid extraction (UMAE) of pectin from pomelo peels. International Journal of Biological Macromolecules, 93, 426-435.

Maran, J.P., Sivakumar, V., Thirugnanasambandham, K., Sridhar, R. (2014). Microwave assisted extraction of pectin from waste Citrullus lanatus fruit rinds. Carbohydrate Polymers, 101, 786791.

Maran, J.P., Swathi, K., Jeevitha, P., Jayalakshmi, J., Ashvini, G. (2015). Microwave-assisted extraction of pectic polysaccharide from waste mango peel. Carbohydrate Polymers, 123, 67-71. 
Pan, X., Niu, G., Liu, H. (2003). Microwaveassisted extraction of tea polyphenols and tea caffeine from green tea leaves. Chemical Engineering and Processing, 42(2), 129-133.

Pham, H.H. (2014). Cây cỏ Việt Nam - Quyển III [Plants in Vietnam - Part III]. Ho Chi Minh city: Youth Publishing House. (In Vietnamese)

Quan, P.T., Hang, T.V., Ha, N.H., De, N.X., Tuyen, T.N. (2006). Microwave-assisted extraction of polyphenols from fresh tea shoot. Journal of Science and Technology Development, 9(8), 69-75.

Quoc, L.P.T., Muoi, N.V. (2016). Microwaveassisted extraction of phenolic compounds from Polygonum multiflorum Thunb. roots. Acta Scientiarum Polonorum Technologia Alimentaria, 15(2), 181-189.

Shirin, A.P.R., Prakash, J. (2010). Chemical composition and antioxidant properties of ginger root (Zingiber officinale). Journal of Medicinal Plants Research, 4(24), 26742679.

Siddiqua, A., Premakumari, K.B., Sultama, R., Vithya, Savitha. (2010). Antioxidant activity and estimation of total phenolic content of Muntingia calabura by colorimetry. International Journal of ChemTech Research, 2(1), 205-208.

Songsungkan, J., Chanthai, S. (2014). Determination of synergic antioxidant activity of the methanol/ethanol extract of allicin in the presence of total phenolics obtained from the garlic capsule compared with fresh and baked garlic clove. International Food Research Journal, 21(6), 2377-2385.

Švarc-Gajic, J., Stojanovic, Z., Carretero, A.S., Román, D.A., Borrás, I., Vasiljevic, I. (2013). Development of a microwaveassisted extraction for the analysis of phenolic compounds from Rosmarinus officinalis. Journal of Food Engineering, 119(3), 525-532.

Szydowska-Czerniak, A., Dianoczki, C., Recseg, K., Karlovits, G., Szyk, E. (2008). Determination of antioxidant capacities of vegetable oil by ferric-ion spectrophotometric methods. Talanta, 76(4), 899-905.

Tomaz, I., Huzanic, N., Preiner, D., Stupic, D., Andabaka, Z., Maletic, E., Kontic, J.K., Asperger, D. (2019). Extraction methods of polyphenol from grapes: Extractions of grape polyphenols. In: Watson, R.R. (Ed.). Polyphenols in Plant - Isolation, Purification and Extract Preparation. Elsevier Academic Press, London, pp. 151167.

Truong, C.H. (2001). 700 bài thuốc trị bệnh bằng gừng, hành, tỏi $[700$ remedies for treatment with Onions, Ginger, Garlic]. Thanh Hoa: Thanh Hoa Publishing House. (In Vietnamese)

Wakte, P.S., Sachin, B.S., Patil, A.A., Mohato, D.M., Band, T.H., Shinde, D.B. (2011). Optimization of microwave, ultra-sonic and supercritical carbon dioxide assisted extraction techniques for curcumin from Curcuma longa. Separation and Purification Technology, 79(1), 50-55.

Wu, T., Yan, J., Liu, R., Marcone, M.F., Aisa, H.A., Tsao, R. (2012). Optimization of microwave-assisted extraction of phenolics from potato and its downstream waste using orthogonal array design. Food Chemistry, 133(4), 1292-1298.

Xia, E., Ai, X., Zang, S.Y., Guan, T.T., Xu X.R., Li, H.B. (2011). Ultrasound-assisted extraction of phillyrin from Forsythia suspensa. Ultrasonics Sonochemistry, 18(2), 549-552.

Yang, L., Jiang, J.G., Li, W.F., Chen, J., Wang, D.Y., Zhu, L. (2009). Optimum extraction Process of polyphenols from the bark of Phyllanthus emblica L. based on the response surface methodology. Journal of Separation Science, 32(9), 1437-1444.

\section{Acknowledgment}

This research was performed at the Institute of Biotechnology and Food Technology, Industrial University of Ho Chi Minh City (Vietnam). The author would like to acknowledge my coworkers, who helped us in this study, including Do Thi Minh Thu, Pham Hoang My Duyen and Hoang Huyen Trang. 